Journal

\title{
Tide-induced seawater-groundwater circulation in a multi-layered coastal leaky aquifer system
}

\author{
Hailong $\mathrm{Li}^{\mathrm{a}, \mathrm{b}, *}$, Jiu Jimmy Jiao ${ }^{\mathrm{b}}$ \\ ${ }^{a}$ Department of Mathematics, Anshan Normal College, Anshan 114005, Liaoning, People's Republic of China \\ ${ }^{\mathrm{b}}$ Department of Earth Sciences, The University of Hong Kong, Pokfulam Road, Hong Kong, People's Republic of China
}

Received 23 April 2002; revised 5 December 2002; accepted 6 December 2002

\begin{abstract}
Mean groundwater levels of a multi-layered coastal leaky aquifer system are considered. The system consists of an unconfined aquifer, a confined aquifer and a semi-permeable layer between them. Both exact asymptotic solutions and approximate perturbation solutions are derived for multi-sinusoidal-component sea tide. At inland places far from the coastline, the perturbation solutions show a good agreement with the exact asymptotic solutions. Due to the watertable-dependent transmissivity of the unconfined aquifer, the mean groundwater levels of the aquifer system stand considerably above the mean sea level even in the absence of net inland recharge of groundwater and rainfall. These lead to landward positive gradients of both the mean watertable and mean head in the region near the coastline, which consequently results in a seawater-groundwater cycle. Seawater is pumped into the unconfined aquifer by the sea tide and divided into two parts. One part returns to the sea driven by the mean watertable gradient. The rest part leaks into the confined aquifer through the semipermeable layer, and returns to the sea through the confined aquifer driven by the mean head gradient. The total discharge through the confined aquifer is significant for coastal leaky aquifer system with typical parameter values. This seawater-groundwater cycle has impacts on better understanding of submarine groundwater discharge and exchange of various chemicals such as nutrients and contaminants in coastal areas. If the observed mean water levels in coastal areas are used for estimating the net inland recharge, the enhancing processes of sea tide on the mean groundwater levels should be taken into account. Otherwise, the net inland recharge will be overestimated.
\end{abstract}

(c) 2003 Elsevier Science B.V. All rights reserved.

Keywords: Coastal leaky aquifer system; Sea tide; Analytical solution; Seawater-groundwater circulation; Submarine groundwater discharge

\section{Introduction}

Interaction between the seawater and groundwater in coastal areas is one of the most important study topics of hydrologists. For example, esti-

\footnotetext{
* Corresponding author. Address: Dept. of Mathematics, Anshan Normal University, Anshan 114005, Liaoning. People's Republic of China. Tel.: + 86-412-5841417; fax: +86-412-2960111.

E-mail address: hlica@hkusua.hku.hk (H. Li).
}

mation of the submarine groundwater discharge (SGWD) and net inland recharge in coastal areas are of great importance for the correct assessment of the role of groundwater in the global water cycle (Moore, 1996; Li et al., 1999; Church, 1996). The influences of sea tide on the mean groundwater levels are one of the aspects immediately related to the SGWD estimation.

For a single coastal unconfined aquifer, the influences of the sea tide on the mean watertable 
have been studied by many researchers (e.g. Philip, 1973; Smiles and Stokes, 1976; Knight, 1981; Parlange et al., 1984; Nielsen, 1990). Philip (1973) derived an exact asymptotic constant solution to the steady periodic nonlinear diffusion problem. As an application of his analytical solution, he considered the mean watertable in a coastal unconfined aquifer bounded by an impermeable bottom and a straight coastline with vertical beach connected to a sinusoidal tidal water body. Assume that the datum is the mean sea level, then, in the absence of net inland recharge of groundwater and rainfall, the mean water table $\bar{W}(x)$ in the unconfined coastal aquifer satisfies (Philip, 1973)

$\lim _{x \rightarrow \infty} \bar{W}(x)=D\left(\sqrt{1+\frac{1}{2} \frac{A^{2}}{D^{2}}}-1\right)$,

where $A$ is the tidal amplitude [L], $D$ is the unconfined aquifer's depth [L] below the mean sea level, and $x$ is the landward distance from the coastline. Based on Eq. (1), Philip (1973) concluded that when $(A / D)^{2}=1$ the inland groundwater level lies above the mean sea level by about $23 \%$ of the tidal amplitude. Philip's (1973) result was derived from Boussinesq's equation, which is based on the Dupuit-Forchheimer (D-F) assumptions that assume groundwater flow to be essentially horizontal. Knight (1981) considered a free-surface problem that takes the vertical flow into account strictly. He proved theoretically that Philip's result exactly holds independent of the validity of the D-F assumptions.

For steady periodic state when there is neither seawater intrusion nor net inland recharge, to maintain water balance, water entering a coastal unconfined aquifer at high tide should be exactly equal to that leaving the aquifer at low tide. The transmissivity of the unconfined aquifer is watertable-dependent. If the mean watertable equalled the mean sea level, the transmissivity of the unconfined aquifer at high tide would be greater than that at lower tide (Fig. 1a). Hence, seawater entering the aquifer at high tide would be more than that leaving the aquifer at low tide, which would result in water imbalance. If the mean watertable is higher than the mean sea level, a greater hydraulic gradient will be generated at low tide, which will compensate for the low transmissivity and increase the amount of water recharging to the sea. Consequently, only when the mean watertable stays above the mean sea level, can the unconfined aquifer maintain correct water balance (Fig. 1b).

Philip's theoretical prediction was examined and confirmed by a Hele-Shaw experiment conducted by Smiles and Stokes (1976). Their experiment curves were consistent with Philip's contention that the root mean square should be effectively constant and about $23 \%$ greater than the mean of the reservoir oscillation for the experiments described there. Parlange et al. (1984) used second-order theory to describe the propagation of steady periodic motion of liquid in porous medium. Their two laboratory experiments, together with analytical and numerical analysis also support Philip's (1973) prediction. Nielsen (1990) developed an approximate analytical solution based on a perturbation method to investigate the mean watertable in the inland region near the coastline. Under the same conditions used by Philip (1973), the mean watertable in the unconfined coastal aquifer can be approximated by (see Eq. (25) of Nielsen (1990))

$\bar{W}_{\text {Nielsen }}(x)=\frac{A^{2}}{4 D}\left(1-\mathrm{e}^{-2 a_{\mathrm{U}} x}\right)$,

where $a_{\mathrm{U}}$ is the wave number, and $x$ is the landward distance from the coastline. The wave number is given by

$a_{\mathrm{U}}=\sqrt{\omega S_{\mathrm{y}} /\left(2 K_{\mathrm{U}} D\right)}$

in which $\omega$ is the tidal angular velocity $\left[\mathrm{T}^{-1}\right], S_{\mathrm{y}}$ and $K_{\mathrm{U}}$ are the unconfined aquifer's specific yield [dimensionless] and hydraulic conductivity [ $\mathrm{LT}^{-1}$ ], respectively. The sinusoidal sea tide is specified as $H_{\text {sea }}(t)=A \cos (\omega t+c)$, where $t$ is the time [T] and $c$ is the tidal phase shift [Radian]. Eq. (2a) shows that at inland places where the dimensionless landward distance $a_{\mathrm{U}} x \gg 1$, the mean watertable will be higher than the mean sea level by $A^{2} /(4 D)$. Using Taylor's expansion

$\sqrt{1+\alpha / 2}=1+\frac{\alpha}{4}+\frac{\alpha^{2}}{32(1+\xi / 2)^{3 / 2}}, 0 \leq \xi \leq \alpha$,

it follows that Eq. (2a) is an approximation to the exact asymptotic constant (1) up to the first order of $\alpha=(A / D)^{2}$. When $\alpha \leq 1$, the truncation error is less than $3.125 \%$.

Nielsen (1990) and Li et al. (2000) also showed that a slope water-land boundary will lead to a much 

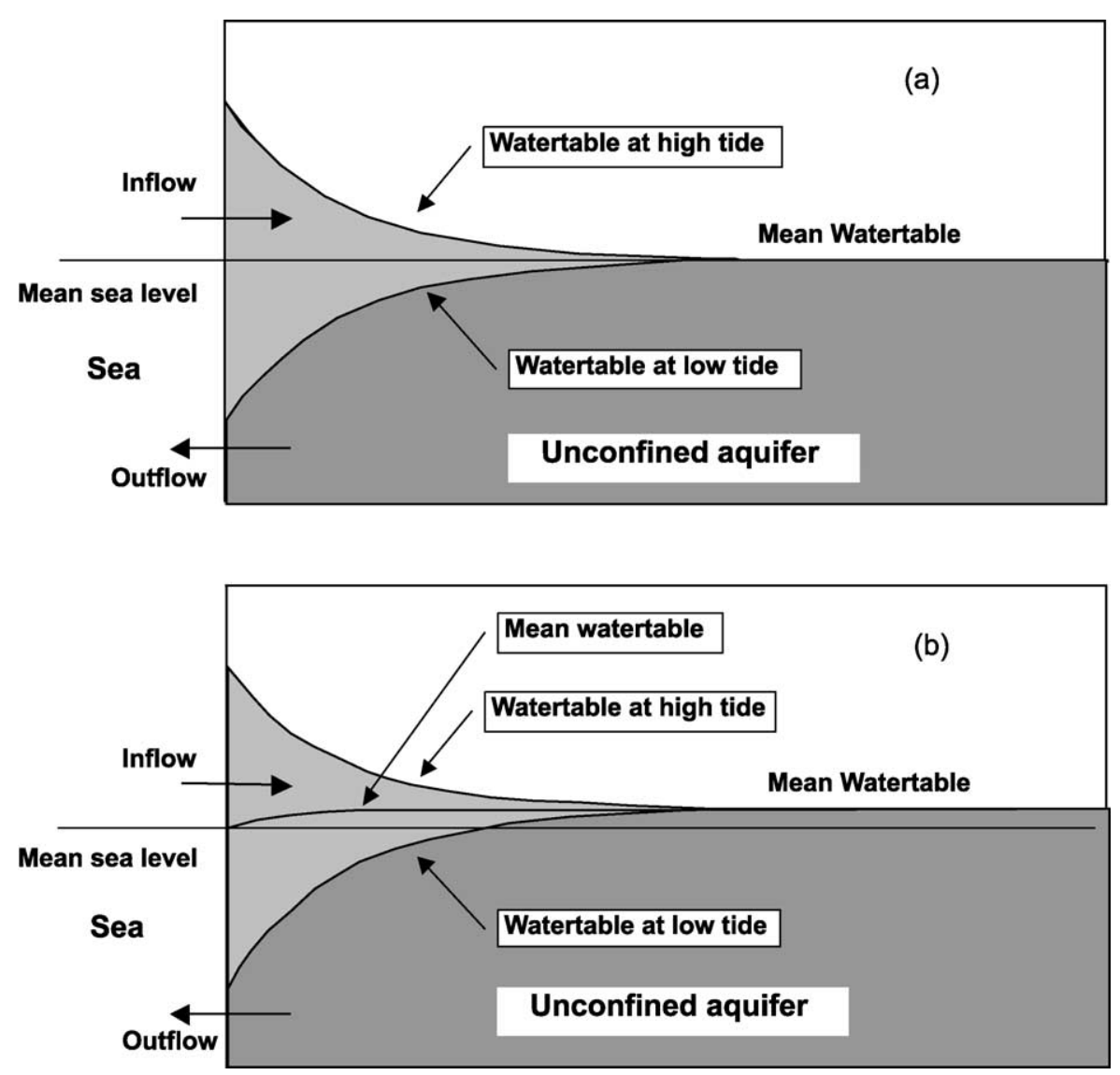

Fig. 1. Explanation to the sea tide-induced mean watertable higher than the mean sea level: (a) Hypothetical situation (mean watertable $=$ mean sea level) and (b) Real situation (mean watertable $>$ mean sea level).

higher mean water table than a vertical one does. Therefore, the influence of tide on the mean water table should be considered when SGWD from a coastal unconfined aquifer is estimated by the mean hydraulic gradient determined by comparing the mean seawater and groundwater levels.

The main limitation of the previous work of Phillip (1973), Smiles and Stokes (1976), Knight (1981), and Parlange et al. (1984) is that they assume the sea tide has only one sinusoidal component. In reality, the sea tide consists of tens of sinusoidal components that include the effects of the sun, moon and earth, etc. (e.g. Melchior, 1978; Pugh, 1987). Due to nonlinearities of the model equations describing the unconfined aquifer, the solution to a single sinusoidal component cannot be used, in general, to superimpose to find the complete solution for the whole sea tide. Therefore, generalization of their work is necessary by taking into account more than one components of the sea tide in the tidal boundary condition. Although Li et al. (2000) considered two tidal constituents, their model focused on the effects of the beach slope on tidal flow in the unconfined aquifer modelled by a linearized Boussinesq equation. Moreover, in many coastal areas, what abuts the sea is usually a multilayered system (e.g. Serfes, 1991; Sheahan, 1977; Chen and Jiao, 1999; Jiao and Tang, 1999). It is interesting to approach the influences of the sea tide on the mean water levels in such a case. Based on such motivations, this paper investigates the tide-induced mean water levels of a coastal multilayered groundwater system consisting of a confined aquifer, an unconfined aquifer, and a semi-permeable 
layer between them. A nonlinear mathematical model is built to describe the relationship between the sea tides, water table in the unconfined aquifer and water head in the confined aquifer. Different sinusoidal components of the sea tide are included in the tidal boundary condition. Exact asymptotic solutions are derived to obtain the information on the mean groundwater levels of the multi-layered aquifer system at inland places far from the coastline. Approximate perturbation solutions are also derived to investigate the behaviour of the mean water levels of the system in the vicinity of the coastline. The solutions are analyzed and discussed.

\section{Mathematical model and definitions of mean water levels}

\subsection{Mathematical model}

Consider a subsurface system consisting of an unconfined aquifer, a confined aquifer and a semipermeable layer between them (Fig. 1). The system satisfies the following assumptions: (a) Each layer is horizontal and homogeneous, and has a vertical boundary with the seawater. The confined aquifer has an impermeable bottom. (b) The horizontal flow in the semi-permeable layer and the vertical flow in the confined aquifer are negligible. (c) The flow in the unconfined aquifer is horizontal, i.e. the DupuitForchheimer assumptions (Bear, 1972) apply. (d) The unconfined aquifer's depth $D$ below the mean sea level is great enough so that the seawater remains connected with the unconfined aquifer at low tide.

Cartesian coordinates $x, z$ will be used, with $z$ taken to be positive vertically upwards. The two interfaces between the semi-permeable layer and the two aquifers are located in the planes $z= \pm b^{\prime} / 2$, where $b^{\prime}$ is the thickness [L] of the semi-permeable layer (see Fig. 2). The water-land vertical boundary is located at $x=0$. Based on assumption (c) and (d), the water table $W(x, t)$ in the unconfined aquifer satisfies the following one-dimensional Boussinesq equation (Bear, 1972)

$S_{\mathrm{y}} \frac{\partial W}{\partial t}=K_{\mathrm{U}} \frac{\partial}{\partial x}\left((W+D) \frac{\partial W}{\partial x}\right)-\left.K^{\prime} \frac{\partial H_{\mathrm{S}}}{\partial z}\right|_{z=\frac{b^{\prime}}{2}}$,

$-\infty<t<\infty, x>0$ and the boundary condition

$\left.W\right|_{x=0}=W_{\text {Tide }}(t)=\sum_{j=1}^{N} A_{j} \cos \left(\omega_{j} t+c_{j}\right)$,

$\lim _{x \rightarrow \infty} \frac{\partial W}{\partial x}=0$

where $K^{\prime}$ and $H_{\mathrm{S}}(x, z, t)$ are the vertical hydraulic conductivity $\left[\mathrm{LT}^{-1}\right]$ and water head $[\mathrm{L}]$ of the semipermeable layer, respectively; $W_{\text {Tide }}(t)$ is the water level [L] of the sea tide; $N$ is the number of the sinusoidal components of the sea tide; $A_{j}, \omega_{j}$ and $c_{j}$ $(j=1, \ldots, N)$ are the amplitude [L], angular velocity $\left[\mathrm{T}^{-1}\right]$ and phase shift of the $j$ th sinusoidal component, respectively. The angular velocities $\omega_{1}, \ldots, \omega_{N}$ are not equal to each other. The datum of the system is set to be the mean sea level. Eq. (4b) describes the tidal boundary condition of $W(x, t)$ at the water-land interface along the coastline, while Eq. (4c) gives a no-flow boundary condition as $x$ approaches infinity, which means that there is no inland recharge far from the coastline.

Based on the assumption (b), the groundwater head $H_{\mathrm{S}}(x, z, t)$ in the semi-permeable layer satisfies

$S_{\mathrm{S}}^{\prime} \frac{\partial H_{\mathrm{S}}}{\partial t}=K^{\prime} \frac{\partial^{2} H_{\mathrm{S}}}{\partial z^{2}}, \quad-\infty<t<\infty,-\frac{b^{\prime}}{2}<z<\frac{b^{\prime}}{2}$,

$\left.H_{\mathrm{S}}(x, z, t)\right|_{z=b^{\prime} / 2}=W(x, t)$,

$\left.H_{\mathrm{S}}(x, z, t)\right|_{z=-b^{\prime} / 2}=H_{\mathrm{C}}(x, t)$;

where $S_{\mathrm{S}}^{\prime}$ is the specific storage $\left[\mathrm{L}^{-1}\right]$ of the semipermeable layer, and $H_{\mathrm{C}}(x, t)$ is the groundwater head of the confined aquifer. Eqs. (5b) and (5c) guarantee the water head continuity at the upper and lower boundaries of the semi-permeable layer.

Based on the assumptions (a) and (b), the groundwater head $H_{\mathrm{C}}(x, z, t)$ in the confined aquifer satisfies

$S \frac{\partial H_{\mathrm{C}}}{\partial t}=T \frac{\partial^{2} H_{\mathrm{C}}}{\partial x^{2}}+\left.K^{\prime} \frac{\partial H_{\mathrm{S}}}{\partial z}\right|_{z=-b^{\prime} / 2}$,

$-\infty<t<\infty, x>0$,

$\left.H_{\mathrm{C}}\right|_{x=0}=W_{\text {Tide }}(t)=\sum_{j=1}^{N} A_{j} \cos \left(\omega_{j} t+c_{j}\right)$,

$\lim _{x \rightarrow \infty} \frac{\partial H_{\mathrm{C}}}{\partial x}=0$ 


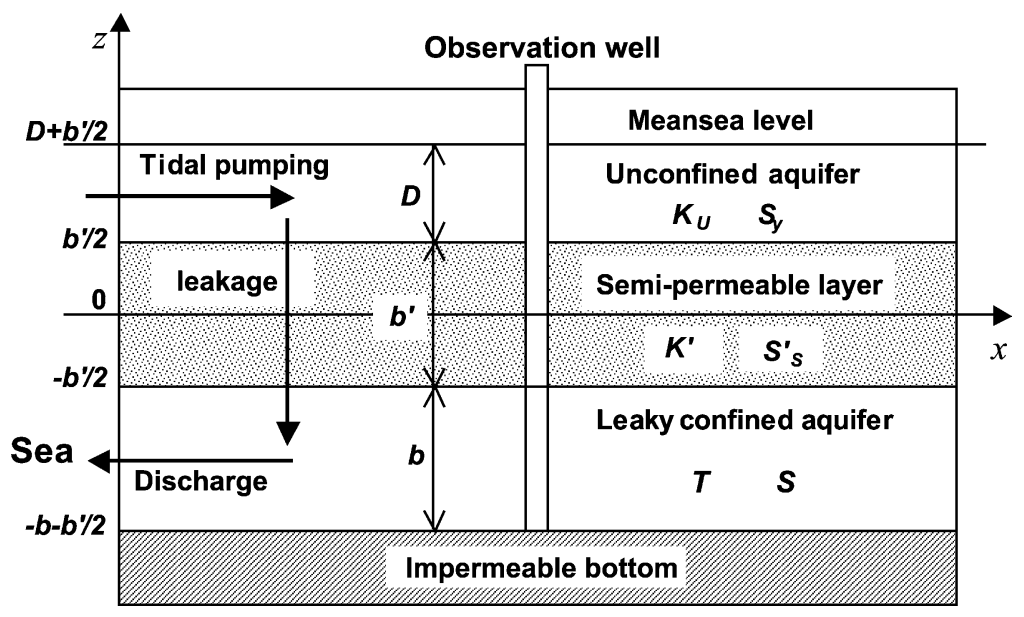

Fig. 2. Schematic representation of a leaky confined aquifer system near open tidal water.

where $S$ and $T$ are the storativity [dimensionless] and the transmissivity $\left[\mathrm{L}^{2} \mathrm{~T}^{-1}\right]$ of the confined aquifer, respectively. Eq. (6b) describes the tidal boundary condition along the coastline, and Eq. (6c) gives the no-flow boundary condition as $x$ approaches infinity, which means that there is no inland recharge far from the coastline.

Let $P_{j}=m_{j} / n_{j}(j=1, \ldots, N)$ be the period [T] of the $j$ th sinusoidal component of the sea tide, where $m_{j}$ and $n_{j}$ are two positive integers prime to each other and $P_{j}$ is measured in hours. Then, with unit of $h^{-1}$, the angular velocity of the $j$ th sinusoidal component is

$\omega_{j}=\frac{2 \pi}{P_{j}}=\frac{2 \pi n_{j}}{m_{j}}, \quad(j=1, \ldots, N)$.

Therefore, the sea tide water level

$W_{\text {Tide }}(t)=\sum_{j=1}^{N} A_{j} \cos \left(\omega_{j} t+c_{j}\right)$

is periodic with respect to the time $t$ with a period of $P$ (in hours) given by

$P=\frac{\min _{\mathrm{CM}}\left(m_{1}, \ldots, m_{N}\right)}{\max _{\mathrm{CD}}\left(n_{1}, \ldots, n_{N}\right)}$,

where $\min _{\mathrm{CM}}\left(m_{1}, \ldots, m_{N}\right)$ denotes the minimum common multiple of $m_{1}, \ldots, m_{N}$, and $\max _{\mathrm{CD}}\left(n_{1}, \ldots, n_{N}\right)$ the maximum common divisor of $n_{1}, \ldots, n_{N}$. In fact, because $n_{j} P / m_{j}$ is an integer for each $j=1, \ldots, N$, it follows that

$$
\begin{aligned}
W_{\text {Tide }}(t+P) & =\sum_{j=1}^{N} A_{j} \cos \left(\omega_{j} t+\omega_{j} P+c_{j}\right) \\
& =\sum_{j=1}^{N} A_{j} \cos \left(\omega_{j} t+2 \pi \frac{n_{j}}{m_{j}} P+c_{j}\right) \\
& =\sum_{j=1}^{N} A_{j} \cos \left(\omega_{j} t+c_{j}\right)=W_{\text {Tide }}(t) .
\end{aligned}
$$

\subsection{Definition of the mean water levels}

Based on Eq. (7d), one can assume that the solutions of the steady-periodic nonlinear system Eqs. (4a)-(6c), $W(x, t), H_{\mathrm{S}}(x, z, t)$ and $H_{\mathrm{C}}(x, t)$, will also be periodic functions of time $t$ with a period of $P$. This assumption is physically reasonable because the periodic sea tide (7b) is the only driving force of the system. Therefore, it is reasonable to define the mean water levels of the leaky aquifer system by

$$
\begin{aligned}
& \bar{W}(x)=\frac{1}{P} \int_{t}^{t+P} W(x, \tau) \mathrm{d} \tau, \\
& \bar{H}_{\mathrm{S}}(x, z)=\frac{1}{P} \int_{t}^{t+P} H_{\mathrm{S}}(x, z, \tau) \mathrm{d} \tau, \\
& \bar{H}_{\mathrm{C}}(x)=\frac{1}{P} \int_{t}^{t+P} H_{\mathrm{C}}(x, \tau) \mathrm{d} \tau,
\end{aligned}
$$


Integrating Eqs. (5a) $-(5 \mathrm{c})$ in the interval $(t, t+P)$ with respect to time $t$, dividing the resulting equations by $P$, and using the periodicity assumption of $W(x, t)$, $H_{\mathrm{S}}(x, z, t)$ and $H_{\mathrm{C}}(x, t)$, yield

$$
\begin{aligned}
& \frac{\partial^{2} \bar{H}_{\mathrm{S}}(x, z)}{\partial z^{2}}=0, \quad-\frac{b^{\prime}}{2}<z<\frac{b^{\prime}}{2}, \\
& \left.\bar{H}_{\mathrm{S}}(x, z)\right|_{z=b^{\prime} / 2}=\bar{W}(x),\left.\bar{H}_{\mathrm{S}}(x, z)\right|_{z=-b^{\prime} / 2}=\bar{H}_{\mathrm{C}}(x) .
\end{aligned}
$$

The solution of Eqs. (9a) and (9b) is

$\bar{H}_{\mathrm{S}}=\frac{z\left(\bar{W}(x)-\bar{H}_{\mathrm{C}}(x)\right)}{b^{\prime}}+\frac{\bar{W}(x)+\bar{H}_{\mathrm{C}}(x)}{2}$.

From Eq. (10a), one obtains

$K^{\prime} \frac{\partial \bar{H}_{\mathrm{S}}}{\partial z}=\frac{K^{\prime}\left(\bar{W}(x)-\bar{H}_{\mathrm{C}}(x)\right)}{b^{\prime}}=L\left(\bar{W}-\bar{H}_{\mathrm{C}}\right)$

where $L=K^{\prime} / b^{\prime}$ is the leakance $\left[\mathrm{T}^{-1}\right]$ of the semipermeable layer (Hantush, 1960).

Integrating Eqs. (4a) and (6a) in the interval $(t, t+P)$ with respect to time $t$, dividing the resulting equations by $P$, and using the equation $(10 \mathrm{~b})$, the identical equation

$(W+D) \frac{\partial W}{\partial x}=\frac{1}{2} \frac{\partial W^{2}}{\partial x}+D \frac{\partial W}{\partial x}$,

and the periodicity assumption of $W(x, t), H_{\mathrm{S}}(x, z, t)$ and $H_{\mathrm{C}}(x, t)$, yield

$K_{\mathrm{U}} \frac{\mathrm{d}^{2}}{\mathrm{~d} x^{2}}\left(\frac{1}{2} W_{\mathrm{ms}}(x)+D \bar{W}(x)\right)-L\left(\bar{W}-\bar{H}_{\mathrm{C}}\right)=0, x>0$,

$T \bar{H}_{\mathrm{C}}^{\prime \prime}+L\left(\bar{W}-\bar{H}_{\mathrm{C}}\right)=0, x>0$,

where $W_{\mathrm{ms}}(x)$ is the mean square of the watertable defined as

$W_{\mathrm{ms}}(x)=\frac{1}{P}\left(\int_{t}^{t+P} W^{2}(x, t) \mathrm{d} t\right)$.

In Sections 3 and 4, the behaviours of the mean water levels defined as Eqs. (8a)-(8c) will be investigated analytically based on the derived Eqs. (10a), (11) and (12).

\section{Asymptotic mean water levels of the system}

This section will focus on the asymptotic behaviours of the mean water levels of the leaky aquifer system when the landward distance from the coastline is so far that the tide-induced oscillations have died out. Exact, asymptotic solutions when $x \rightarrow \infty$ will be derived and discussed.

\subsection{Exact asymptotic solutions} as $x \rightarrow \infty$ when $L>0$

Adding Eqs. (11) and (12), yields $f^{\prime \prime}(x)=0, x>0$ where

$f(x)=\frac{K_{\mathrm{U}}}{2} W_{\mathrm{ms}}(x)+D K_{\mathrm{U}} \bar{W}(x)+T \bar{H}_{\mathrm{C}}(x)$

The general solution of Eq. (14a) is $f(x)=c_{1}+c_{2} x$. From the no-flow boundary condition Eqs. (4c) and (6c), it can be easily deduced that $\lim _{x \rightarrow \infty} f^{\prime}(x)=0$, which implies $c_{2}=0$. Therefore, one has

$f(x)=c_{1}=f(0)=K_{\mathrm{U}}\left[W_{\mathrm{ms}}(0) / 2+D \bar{W}(0)\right]+T \bar{H}_{\mathrm{C}}(0)$.

Using the tidal boundary conditions (4b) and (6b), one obtains

$\bar{W}(0)=\bar{H}_{\mathrm{C}}(0)=0$.

Using Eqs. (4b) and (13), one finds

$$
\begin{aligned}
W_{\mathrm{ms}}(0)= & \frac{1}{P}\left(\int_{t}^{t+P} W^{2}(0, \tau) \mathrm{d} \tau\right) \\
= & \frac{1}{P} \int_{t}^{t+P}\left(\sum_{j=1}^{N} A_{j} \cos \left(\omega_{j} \tau+c_{j}\right)\right)^{2} \mathrm{~d} \tau \\
= & \frac{1}{P} \int_{t}^{t+P} \sum_{i, j=1}^{N} A_{i} A_{j} \cos \left(\omega_{i} \tau+c_{i}\right) \cos \left(\omega_{j} \tau+c_{j}\right) \mathrm{d} \tau \\
= & \frac{1}{P} \int_{t}^{t+P}\left[\sum_{j=1}^{N} A_{j}^{2} \cos ^{2}\left(\omega_{j} \tau+c_{j}\right)\right. \\
& \left.+2 \sum_{1 \leq i<j \leq N} A_{i} A_{j} \cos \left(\omega_{i} \tau+c_{i}\right) \cos \left(\omega_{j} \tau+c_{j}\right)\right] \mathrm{d} \tau .
\end{aligned}
$$

Substituting the trigonometric identities

$$
\begin{aligned}
& 2 \cos \left(\omega_{i} \tau+c_{i}\right) \cos \left(\omega_{j} \tau+c_{j}\right) \\
& =\cos \left[\left(\omega_{i} \tau+c_{i}\right)-\left(\omega_{j} \tau+c_{j}\right)\right] \\
& \quad+\cos \left[\left(\omega_{i} \tau+c_{i}\right)+\left(\omega_{j} \tau+c_{j}\right)\right]
\end{aligned}
$$


into Eq. (14e), because $\omega_{k} P=2 \pi n_{k} P / m_{k}$, and $n_{k} P / m_{k}$ is an integer for each $k=1, \ldots, N$ according to Eqs. (7a) and $(7 \mathrm{c})$, one can easily find that

$$
\int_{t}^{t+P} \cos \left(\omega_{i} \tau+c_{i}\right) \cos \left(\omega_{j} \tau+c_{j}\right) \mathrm{d} \tau= \begin{cases}P / 2, & \text { if } i=j, \\ 0, & \text { if } i \neq j .\end{cases}
$$

Substituting Eq. (14f) into Eq. (14e), one obtains

$2 W_{\mathrm{ms}}(0)=\sum_{j=1}^{N} A_{j}^{2 \text { def. }}=A_{\Sigma}^{2}$.

Eventually, from Eqs. (14b), (14d) and (14g) one finds

$f(x)=\frac{1}{4} K_{\mathrm{U}} A_{\Sigma}^{2}, x \geq 0$.

Integrating Eq. (12) in the interval $(x, x+X)$, let $X \rightarrow \infty$ and then use the no-flow boundary condition $(6 c)$, one obtains

$T \bar{H}_{\mathrm{C}}^{\prime}(x)=L \int_{x}^{\infty}\left[\bar{W}(\xi)-\bar{H}_{\mathrm{C}}(\xi)\right] \mathrm{d} \xi$.

Using Eq. (15) and the no-flow boundary conditions (4c) and (6c), one can show that (see Appendix A for the proof)

$\lim _{x \rightarrow \infty}\left[\bar{W}(x)-\bar{H}_{\mathrm{C}}(x)\right]=0$ if $L>0$.

If the landward distance $x$ is great enough, all the tide-induced oscillations will die out. This implies

$\lim _{x \rightarrow \infty}\left[W_{\mathrm{ms}}(x)-W^{2}(x, t)\right]=0$,

$\lim _{x \rightarrow \infty}[\bar{W}(x)-W(x, t)]=0$,

$\lim _{x \rightarrow \infty}\left[\bar{H}_{\mathrm{C}}(x)-H_{\mathrm{C}}(x, t)\right]=0$.

From Eqs. (14b) and (14h), one has

$$
\begin{aligned}
\frac{1}{4} K_{\mathrm{U}} A_{\Sigma}^{2}= & \frac{K_{\mathrm{U}}}{2} W_{\mathrm{ms}}(x)+D K_{\mathrm{U}} \bar{W}(x)+T \bar{H}_{\mathrm{C}}(x) \\
= & \frac{K_{\mathrm{U}}}{2}\left(W_{\mathrm{ms}}-W^{2}\right)+D K_{\mathrm{U}}(\bar{W}-W) \\
& +T\left(\bar{H}_{\mathrm{C}}-\bar{W}\right)+T(\bar{W}-W)+\frac{K_{\mathrm{U}}}{2} W^{2} \\
& +D K_{\mathrm{U}} W+T W .
\end{aligned}
$$

Let $x \rightarrow \infty$ in Eq. (16e), and use Eqs. (16a)-(16d), it follows that

$$
\lim _{x \rightarrow \infty}\left(\frac{K_{\mathrm{U}}}{2} W^{2}+D K_{\mathrm{U}} W+T W\right)=\frac{1}{4} K_{\mathrm{U}} A_{\Sigma}^{2} \text {, if } L>0 .
$$

Eq. (16f) implies that as $x \rightarrow \infty, W(x, t)$ tends to a constant $c$ that satisfies

$K_{\mathrm{U}} c^{2} / 2+\left(D K_{\mathrm{U}}+T\right) c-K_{\mathrm{U}} A_{\Sigma}^{2} / 4=0$, if $L>0$.

Neglecting the negative root of Eq. (16g) which is physically unrealistic, one eventually obtains

$$
\begin{aligned}
& \lim _{x \rightarrow \infty} W(x, t)=\lim _{x \rightarrow \infty} \bar{W}(x) \\
& \quad=\left(D+T / K_{\mathrm{U}}\right)\left(\sqrt{1+\alpha_{L} / 2}-1\right), \text { if } L>0
\end{aligned}
$$

where $\alpha_{L}$ is a dimensionless parameter given by

$\alpha_{L}=\frac{K_{\mathrm{U}}^{2} A_{\Sigma}^{2}}{\left(D K_{\mathrm{U}}+T\right)^{2}}=\frac{K_{\mathrm{U}}^{2}}{\left(D K_{\mathrm{U}}+T\right)^{2}} \sum_{i=1}^{N} A_{i}^{2}$.

By means of Eqs. (16a), (16d) and (17a), one has

$$
\begin{aligned}
& \lim _{x \rightarrow \infty} H_{\mathrm{C}}(x, t)=\lim _{x \rightarrow \infty} \bar{H}_{\mathrm{C}}(x) \\
& \quad=\left(D+T / K_{\mathrm{U}}\right)\left(\sqrt{1+\alpha_{L} / 2}-1\right), \text { if } L>0 .
\end{aligned}
$$

\subsection{Exact asymptotic solutions as $x \rightarrow \infty$ when $L=0$}

Philip's (1973) exact asymptotic solution (1) considers only one single unconfined aquifer with impermeable bottom, which is equivalent to the situation in this paper when the semi-permeable layer is replaced by a completely impermeable layer, i.e. $L=0$. Substituting $L=0$ into Eq. (11), integrating the resulting equation and using the boundary conditions (4b) and (4c), yield

$$
\frac{1}{2} W_{\mathrm{ms}}(x)+D \bar{W}(x)=\frac{1}{2} W_{\mathrm{ms}}(0)+D \bar{W}(0)=\frac{1}{4} A_{\Sigma}^{2} .
$$

By means of Eqs. (18a), (16b) and (16c), one obtains $\lim _{x \rightarrow \infty} W(x, t)=\lim _{x \rightarrow \infty} \bar{W}(x)=D\left(\sqrt{1+\alpha_{0} / 2}-1\right)$,

if $L=0$ 
where $\alpha_{0}$ is a dimensionless parameter given by

$\alpha_{0}=\frac{A_{\Sigma}^{2}}{D^{2}}=\frac{1}{D^{2}} \sum_{i=1}^{N} A_{i}^{2}$.

Eq. (18b) is a generalization of Philip's (1973) solution (1) in the sense that Eq. (18b) considers all the sinusoidal components of the sea tide. Substituting $L=0$ into Eq. (12) and using the boundary conditions $(6 b)$ and $(6 c)$, yield

$\bar{H}_{\mathrm{C}}(x) \equiv 0$, if $L=0$,

which implies that the aquifer's mean water level equals the mean sea level only when the aquifer is governed by linear equation and there is no net flux.

\subsection{Discussion of the exact asymptotic solutions}

Solutions (17a) and (17c) show that, in inland places far from the coastline, the mean water levels of both the unconfined aquifer and the confined aquifer will be higher than the mean sea level by the same constant. This phenomenon is due to the watertabledependent transmissivity of the unconfined aquifer and the leakage of the semi-permeable layer. The watertable-dependent transmissivity of the unconfined aquifer, as mentioned in Section 1, will lead to a mean watertable higher than the mean sea level. Due to leakage through the semi-permeable layer, the mean head of the underlying aquifer will increase accordingly. These lead to landward positive gradients of both the mean watertable and mean head in the region near the coastline. Therefore, a groundwater-seawater cycle is formed. Seawater is pumped into the unconfined aquifer by the sea tide. Then, part of it returns to the sea driven by the mean watertable gradient. The rest leaks into the confined aquifer through the semi-permeable layer, and returns to the sea through the confined aquifer driven by the mean head gradient. The leakage from the semi-permeable layer is the only source of the discharge through the confined aquifer because there is no inland recharge in the aquifer system.

Using Taylor's expansion (3), the exact asymptotic water levels (17a) and (17c) can be approximated by

$$
\begin{aligned}
\lim _{x \rightarrow \infty} \bar{W}(x) & =\lim _{x \rightarrow \infty} \bar{H}_{\mathrm{C}}(x) \approx \frac{K_{\mathrm{U}} A_{\Sigma}^{2}}{4\left(D K_{\mathrm{U}}+T\right)} \\
& =\frac{K_{\mathrm{U}}}{4\left(D K_{\mathrm{U}}+T\right)} \sum_{i=1}^{N} A_{i}^{2}
\end{aligned}
$$

with a truncation error relative to $D+T / K_{\mathrm{U}}$ being less than $\alpha_{L}^{2} / 32$. From assumption (d), $\alpha_{L}^{2}$ is usually less than 1, so Eq. (19) has adequate accuracy. For example, consider a coastal leaky aquifer system with parameters $T_{\mathrm{U}}=T=10 \mathrm{~m}^{2} / \mathrm{h}$, $D=1.25 \mathrm{~m}, \sum_{j=1}^{N} A_{j}^{2}=1 \mathrm{~m}^{2}$, the exact solutions $(17 \mathrm{a})-(17 \mathrm{c})$ shows that the exact asymptotic mean water level is $0.098076 \mathrm{~m}$, the approximate solution (19) gives a value of $0.10 \mathrm{~m}$. The error is very small.

According to solutions $(17 a)-(17 c)$ or (19), the asymptotic groundwater level of the leaky aquifer system is independent of the magnitude of the leakance of the semi-permeable layer. This is because the asymptotic groundwater level higher than the mean sea level is due to a positive difference between the inflow and outflow in a tidal period at the tidal boundary of the unconfined aquifer, which is independent of the magnitude of the leakance of the semi-permeable layer.

It is well known that Boussinesq's equation (4a) can be linearized approximately when the tidal amplitudes is much less than the aquifer's depth $D$ under the mean sea level (e.g. Bear 1972). Solutions (17a)-(18d) show that the linearization is valid in the sense that the increase of mean groundwater levels of the aquifer system, whose magnitude has the order of $A_{\Sigma} / D$, is negligible for small $A_{\Sigma} / D$.

\section{Perturbation solutions for thin semi-permeable layer and small leakage}

\subsection{Perturbation solutions}

In order to investigate the mean water levels of the leaky aquifer system in the vicinity of the coastline, approximate perturbation solutions will be derived in this section. The system $(4 a)-(6 c)$ is 
$\bar{W}(x) \approx \sum_{j=1}^{N} \frac{A_{j}^{2}}{2 D}\left[\frac{T_{\mathrm{U}}}{2\left(T_{\mathrm{U}}+T\right)}+\frac{T}{\left(T_{\mathrm{U}}+T\right)} \frac{\exp \left(-x \sqrt{\frac{L}{T}+\frac{L}{T_{\mathrm{U}}}}\right)}{\left(2-\varepsilon_{j}\left(1+T_{\mathrm{U}} / T\right)\right)}-\frac{\left(2-\varepsilon_{j} T_{\mathrm{U}} / T\right) \exp \left(-2 a_{j} x\right)}{2\left(2-\varepsilon_{j}\left(1+T_{\mathrm{U}} / T\right)\right)}\right]$,

$\bar{H}_{\mathrm{C}}(x) \approx \sum_{j=1}^{N} \frac{A_{j}^{2}}{2 D}\left[\frac{T_{\mathrm{U}}}{2\left(T_{\mathrm{U}}+T\right)}-\frac{T_{\mathrm{U}}}{\left(T_{\mathrm{U}}+T\right)} \frac{\exp \left(-x \sqrt{\frac{L}{T}+\frac{L}{T_{U}}}\right)}{\left(2-\varepsilon_{j}\left(1+T_{\mathrm{U}} / T\right)\right)}+\frac{\varepsilon_{j} T_{\mathrm{U}} \exp \left(-2 a_{j} x\right)}{2\left(2 T-\varepsilon_{j}\left(T+T_{\mathrm{U}}\right)\right)}\right]$,

very complex because it includes many aquifer parameters. For the sake of succinctness, assume that the semi-permeable layer's storage is negligible (e.g. a thin semi-permeable layer) and the leakage is small $\left(\sum_{j=1}^{N} L /\left(\omega_{j} S_{\mathrm{y}}\right) \ll 1\right)$. Under such assumptions the following perturbation solutions can be obtained (see Appendix B for the derivation)

where $T_{\mathrm{U}}=K_{\mathrm{U}} D, a_{j}=\sqrt{\omega_{j} S_{\mathrm{y}} /\left(2 K_{\mathrm{U}} D\right)}$ is the wave number corresponding to the $j$ th sinusoidal component, $\varepsilon_{j}$ is a small dimensionless constant defined as

$\varepsilon_{j}=\frac{L}{\omega_{j} S_{\mathrm{y}}}=\frac{u_{j}}{2\left(S_{\mathrm{y}} / S\right)}$

with $u_{j}=L /\left(\omega_{j} S\right)$ being the dimensionless leakage ( $\mathrm{Li}$ and Jiao, 2001). The mean head of the semipermeable layer $\bar{H}_{\mathrm{S}}(x)$ is given by Eq. (10a).

For real aquifer systems, one has $S_{\mathrm{y}} \sim 10^{-1}, S \sim$ $\left(10^{-5}-10^{-3}\right)$ (Todd, 1980). The major sinusoidal components of the sea tide are usually semidiurnal and diurnal, so the range of $u_{j}$ is from 0 to 20 for real leaky aquifer systems ( $\mathrm{Li}$ and Jiao, 2001). Therefore, according to Eq. (22), the range of $\varepsilon_{j}$ is $10^{-3}-10^{-1}$. This validates to a certain extent the small leakage assumption $\left(\sum_{j=1}^{N} \varepsilon_{j} \ll 1\right)$.

\subsection{Discussion}

It may be interesting to have some idea about how the leakage from the unconfined aquifer to the confined aquifer changes with the inland distance. Based on Darcy's law and Eqs. (10b), (20) and (21), the time-averaged leakage flux $F_{\mathrm{L}}(x)$ through the semi-permeable layer is defined as

$$
\begin{aligned}
F_{\mathrm{L}}(x) & =\left.\frac{K^{\prime}}{P} \int_{t}^{t+P} \frac{\partial H_{\mathrm{S}}}{\partial z}\right|_{z=-b^{\prime} / 2} \mathrm{~d} t=K^{\prime} \frac{\partial \bar{H}_{\mathrm{S}}}{\partial z}=L\left(\bar{W}-\bar{H}_{\mathrm{C}}\right) \\
& =\frac{L T}{2 D} \sum_{j=1}^{N} \frac{A_{j}^{2}\left[\exp \left(-x \sqrt{\frac{L}{T}+\frac{L}{T_{\mathrm{U}}}}\right)-\exp \left(-2 a_{j} x\right)\right]}{2 T-\varepsilon_{j}\left(T+T_{\mathrm{U}}\right)} .
\end{aligned}
$$

Because there is no inland recharge, the discharge $Q_{\mathrm{C}}$ from the confined aquifer equals the total leakage through the semi-permeable layer, i.e.

$Q_{\mathrm{C}}=\int_{0}^{\infty} F_{\mathrm{L}}(x) \mathrm{d} x=\frac{T}{2 D} \sum_{j=1}^{N} \frac{A_{j}^{2}\left(\sqrt{L T T_{\mathrm{U}} /\left(T_{\mathrm{U}}+T\right)}-\varepsilon_{j} a_{j} T_{\mathrm{U}}\right)}{2 T-\varepsilon_{j}\left(T+T_{\mathrm{U}}\right)}$.

One can also calculate

$Q_{\mathrm{C}}=\left.\frac{T}{P} \int_{t}^{t+P} \frac{\partial H_{\mathrm{C}}}{\partial x}\right|_{x=0} \mathrm{~d} t=T \bar{H}_{\mathrm{C}}^{\prime}(0)$

by directly using Eq. (21). The result is the same as Eq. (24).

To see how the leakage flux $F_{\mathrm{L}}(x)$ changes with landward distance $x$ and how large the discharge $Q_{\mathrm{C}}$ will be, consider a coastal leaky aquifer system with typical parameters $T_{\mathrm{U}}=T=50 \mathrm{~m}^{2} / \mathrm{h}, D=2 \mathrm{~m}$, $N=1, A_{1}=1 \mathrm{~m}, S_{\mathrm{y}}=0.3, \omega_{1}=0.5 \mathrm{~h}^{-1}$ (semidiurnal sea tide), $L=0.00075-0.0075 \mathrm{~h}^{-1}$. These data lead to $a_{1}=\sqrt{\omega_{1} S_{\mathrm{y}} /\left(2 T_{\mathrm{U}}\right)}=0.03873 \mathrm{~m}^{-1}, \quad u=\varepsilon_{1}=L /\left(\omega_{1} S_{\mathrm{y}}\right)$ $=0.005-0.05$. Fig. 3 shows how the leakage flux $F_{\mathrm{L}}(x)$ changes with the landward distance $x$ for different values of $u$. 


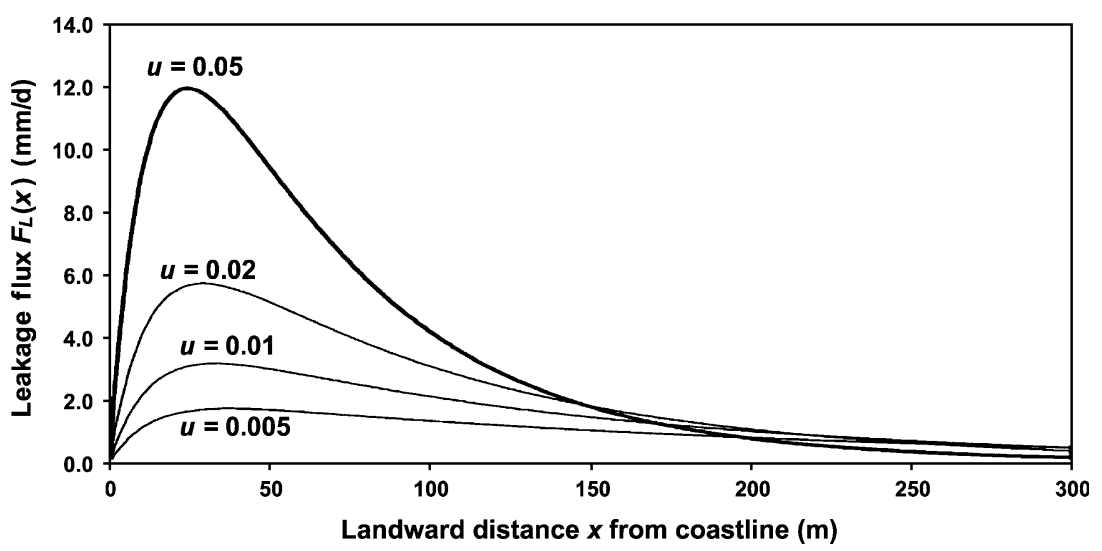

Fig. 3. Change of the leakage flux $F_{\mathrm{L}}(x)$ in the confined aquifer with the landward distance $x$ for different values of the dimensionless leakage $u$.

The leakage flux $F_{\mathrm{L}}(x)$ is zero at the coastline $x=0$ because the water levels in the unconfined and confined aquifers equal the sea level. It reaches its maximum at a certain point and then decreases to zero as $x \rightarrow \infty$. The maximum leakage flux decreases with $u$. When $u$ is smaller, the leakage will occur over a greater range of inland distance.

As the dimensionless leakage $u$ increases from 0.005 to 0.05 , the discharge $Q_{\mathrm{C}}$ from the confined aquifer increases from 0.38 to $1.06 \mathrm{~m}^{2} \mathrm{~d}^{-1}$, which means that the groundwater entering the sea from the confined aquifer per day per meter of the coastline is $0.38-1.06 \mathrm{~m}^{3}$. Considering that most coastal aquifers have long coastlines, this is a considerable amount.

One of the assumptions of this study is that there are neither rainfall infiltrations into the unconfined aquifer nor net groundwater recharges into the aquifers from inland places far from the coast. In reality, however, there usually exist the rainfall infiltration and other inland recharges to the unconfined and confined aquifers, which may influence the direction of the leakage flux and the circulation, i.e. the sign of $F_{\mathrm{L}}$. In this case, because the local leakage flux direction is determined by the difference of the local watertable of the unconfined aquifer and the local hydraulic head of the confined aquifer, the sign of the leakage flux may be negative in some inland places and positive at other places. It is obvious that the rainfall infiltration and other inland recharges into the unconfined aquifer will lead to the increase of the leakage flux. On the contrary, inland recharges into the confined aquifer will result in the decrease of leakage flux. Sufficiently great inland recharge into the confined aquifer will lead to negative leakage flux-leakage flux from the confined aquifer into the unconfined aquifer at some inland places.

Let the landward distance $x$ approach infinite in Eqs. (20), (21) and (10a), one obtains

$$
\begin{aligned}
\lim _{x \rightarrow \infty} \bar{W} & =\lim _{x \rightarrow \infty} \bar{H}_{\mathrm{S}}=\lim _{x \rightarrow \infty} \bar{H}_{\mathrm{C}}=\frac{T_{\mathrm{U}}}{4 D\left(T_{\mathrm{U}}+T\right)} \sum_{j=1}^{N} A_{j}^{2} \\
& =\frac{K_{\mathrm{U}}}{4\left(D K_{\mathrm{U}}+T\right)} \sum_{j=1}^{N} A_{j}^{2} .
\end{aligned}
$$

Comparison of Eqs. (25) and (19) reveals that at inland places far from the coastline, the perturbation solutions equal the approximate Taylor expansion of the exact asymptotic solutions with a truncation error less than $\alpha_{L}^{2} / 32$ relative to $D+$ $T / K_{\mathrm{U}}$, where $\alpha_{L}$ is defined as Eq. (17b). From assumption (d), $\alpha_{L}$ is usually less than 1 . So the relative error of Eq. (25) is less than $3.125 \%$ and can be neglected. For example, for the above aquifer system discussed in Fig. 3, the exact solutions (17a) and (17c) show that the asymptotic mean water level far inland is $0.06202 \mathrm{~m}$, the perturbation solutions (20), (21) or (25) give a value of $0.0625 \mathrm{~m}$.

Solution (2a) by Nielsen (1990) assumed that the unconfined aquifer has an impermeable bottom, i.e. 
the leakance $L=0$. Substituting $L=0$ into Eqs. (20) and (21) yields

$$
\left.\bar{W}(x)\right|_{L=0} \approx \sum_{j=1}^{N} \frac{A_{j}^{2}}{4 D}\left(1-\mathrm{e}^{-2 a_{j} x}\right),\left.\quad \bar{H}_{\mathrm{C}}(x)\right|_{L=0} \equiv 0 .
$$

Eq. (26) is a generalization of Nielsen's solution (2a) in the sense that Eq. (26) considers all the sinusoidal components of the sea tide.

\section{Summary}

This paper investigates the influences of the sea tide on the mean water levels in a multi-layered coastal aquifer system with a confined aquifer, an unconfined aquifer, and a semi-permeable layer between them. Exact asymptotic solutions and approximate perturbation solutions are derived for multi-sinusoidal-component sea tide. At inland places where the distance from the coastline is so far that all the tide-induced oscillations have died out, the mean water levels in both the unconfined and confined aquifers approach the same constant considerably higher than the mean sea level. Exact asymptotic solutions show that this constant water level depends on the amplitudes of the sinusoidal components of the sea tide, the confined aquifer's hydraulic transmissivity, the unconfined aquifer's permeability and the depth below the mean sea level, and that it is independent of the magnitude of the leakance of the semi-permeable layer. As the landward distance approaches infinite, the perturbation solutions in both aquifers tend to the same constant that is found to be a Taylor-expansion approximation to the exact asymptotic constant with a relative truncation error less than $3.125 \%$. Nielsen's mean watertable solution (2a) is the special case for singlesinusoidal-component sea tide when the middle layer becomes impermeable.

Due to the watertable-dependent transmissivity of the unconfined aquifer, the mean water levels of the unconfined and confined aquifer higher than the mean sea level lead to positive landward gradients of the mean water levels, which result in a seawatergroundwater cycle in the region near the coastline. Seawater is pumped into the unconfined aquifer by the sea tide and divided into two parts. One part returns to the sea driven by the mean watertable gradient. The rest part leaks into the confined aquifer through the semi-permeable layer, and returns to the sea through the confined aquifer driven by the mean head gradient. The perturbation solutions show that the discharge through the confined aquifer is significant for typical aquifer parameter values. The seawater-groundwater circulation described in this paper has impacts on the exchange and movement of chemicals such as nutrients and contaminants in the coastal areas. This circulation provides also insights into better understanding the mechanism regarding SGWD. If the observed mean water levels in coastal areas are used for estimating the net inland recharge, the enhancing processes of sea tide on the mean groundwater levels should be taken into account. Otherwise, the net inland recharge will be overestimated.

According to Nielsen (1990) and Li et al. (2000), a slope water-land boundary of the coastal aquifer will lead to much higher watertable in the unconfined aquifer than a vertical water-land boundary does. In reality, the water-land boundary of the coastal aquifer systems is usually a slope. Hence, the phenomenon revealed in this paper may be reinforced in multi-layered coastal aquifer systems with sloping beach.

\section{Acknowledgements}

This research is supported by Dr Stephen S.F. Hui Trust Fund at the University of Hong Kong. The authors are grateful for the helpful comments of Dr Ling Li.

\section{Appendix A. Proof of Eq. (16a)}

Suppose Eq. (16a) does not hold, then there exists a fixed number $c_{0}>0$, and a series of $x_{j}(j=1,2, \ldots)$ that tends to infinite, such that

$\left|E\left(x_{j}\right)\right|>c_{0}, \quad(j=1,2, \ldots)$,

holds, where $E(x)=\bar{W}(x)-\bar{H}_{\mathrm{C}}(x)$. From the noflow boundary conditions $(4 c)$ and $(6 c)$, there exists 
an integer $J$, such that for each $j \geq J, x_{J}$ is great enough for the following inequalities to hold

$\left|\frac{\mathrm{d} W(x, t)}{\mathrm{d} x}\right|<\frac{c_{0}^{2}}{2}, \quad\left|\frac{\mathrm{d} H_{\mathrm{C}}(x, t)}{\mathrm{d} x}\right|<\frac{c_{0}^{2}}{2}$,

$\forall t \in(-\infty, \infty), x \geq x_{J}$

Using Eq. (A2) and definitions of mean water levels (8a) and (8c), it follows that

$$
\begin{aligned}
\left|\frac{\mathrm{d} E}{\mathrm{~d} x}\right| & \leq\left|\frac{\mathrm{d} \bar{W}}{\mathrm{~d} x}\right|+\left|\frac{\mathrm{d} \bar{H}_{\mathrm{C}}}{\mathrm{d} x}\right| \\
& \leq \frac{1}{P} \int_{t}^{t+P}\left(\left|\frac{\partial W}{\partial x}\right|+\left|\frac{\partial H_{\mathrm{C}}}{\partial x}\right|\right) t \leq c_{0}^{2}, x \geq x_{J} .
\end{aligned}
$$

Using Eqs. (A1) and (A3), when $x_{j} \geq x_{J}+1 / c_{0}$, one has

$$
\begin{aligned}
& \int_{x_{j}-1 / c_{0}}^{x_{j}+1 / c_{0}}\left(\bar{W}-\bar{H}_{\mathrm{C}}\right) \mathrm{d} x \\
& =\int_{x_{j}-1 / c_{0}}^{x_{j}+1 / c_{0}} E(x) \mathrm{d} x \\
& =\int_{x_{j}-1 / c_{0}}^{x_{j}+1 / c_{0}}\left[\int_{x_{j}}^{x} \frac{\mathrm{d} E(\xi)}{\mathrm{d} \xi} \mathrm{d} \xi+E\left(x_{j}\right)\right] \mathrm{d} x \\
& >2+\int_{x_{j}-1 / c_{0}}^{x_{j}+1 / c_{0}}\left[\int_{x_{j}}^{x} \frac{\mathrm{d} E(\xi)}{\mathrm{d} \xi} \mathrm{d} \xi\right] \mathrm{d} x \\
& \geq 2-\int_{x_{j}-1 / c_{0}}^{x_{j}+1 / c_{0}}\left|\int_{x_{j}}^{x} \frac{\mathrm{d} E(\xi)}{\mathrm{d} \xi} \mathrm{d} \xi\right| \mathrm{d} x \\
& \geq 2-\int_{x_{j}-1 / c_{0}}^{x_{j}}\left[\int_{x}^{x_{j}}\left|\frac{\mathrm{d} E(\xi)}{\mathrm{d} \xi}\right| \mathrm{d} \xi\right] \mathrm{d} x \\
& \quad-\int_{x_{j}}^{x_{j}+1 / c_{0}}\left[\int_{x_{j}}^{x}\left|\frac{\mathrm{d} E(\xi)}{\mathrm{d} \xi}\right| \mathrm{d} \xi\right] \mathrm{d} x \\
& \geq 2-\int_{x_{j}-1 / c_{0}}^{x_{j}}\left[\int_{x}^{x_{j}} c_{0}^{x_{j}} \mathrm{~d} \xi\right] \mathrm{d} x \\
& \left.x_{x_{j}}^{x} c_{0}^{2} \mathrm{~d} \xi\right] \mathrm{d} x=1 . \\
& =2
\end{aligned}
$$

Eq. (A4) is in contradiction with the convergence of the integral $\int_{x}^{\infty}\left[\bar{W}(\xi)-\bar{H}_{\mathrm{C}}(\xi)\right] \mathrm{d} \xi$ in the right-hand side of Eq. (15).

\section{Appendix B. Derivation of perturbation solutions}

Neglecting the storage of semi-permeable layer, from Eqs. $(5 \mathrm{a})-(5 \mathrm{c})$ one obtains

$K^{\prime} \frac{\partial H_{\mathrm{S}}}{\partial z}=\frac{K^{\prime}}{b^{\prime}}\left[W(x, t)-H_{\mathrm{C}}(x, t)\right]=L\left(W-H_{\mathrm{C}}\right)$

Let $\delta=A_{\Sigma} / D$ be the perturbation parameter, and let

$W(x, t)=W_{0}(x, t)+\delta W_{1}(x, t)+\delta^{2} W_{2}(x, t) \ldots$,

$H_{\mathrm{C}}(x, t)=H_{\mathrm{C} 0}(x, t)+\delta H_{\mathrm{C} 1}(x, t)+\delta^{2} H_{\mathrm{C} 2}(x, t) \ldots$,

inserting Eqs. (A6) and (A7) into Eqs. (4a)-(4c) and (6a) $-(6 \mathrm{c})$, and separating terms of equal order in $\delta$, one finds that $W_{0}=H_{\mathrm{C} 0} \equiv 0$ from equations of order $\delta^{0}$, while $W_{i}$ and $H_{\mathrm{C} i}(i=1,2)$ satisfy the following system of equations.

Order $\delta^{1}$ :

$S_{\mathrm{y}} \frac{\partial W_{1}}{\partial t}=K_{\mathrm{U}} D \frac{\partial^{2} W_{1}}{\partial x^{2}}-L\left(W_{1}-H_{\mathrm{C} 1}\right)$

$-\infty<t<\infty, x>0$,

$\left.W_{1}\right|_{x=0}=\frac{D}{A_{\Sigma}} \sum_{j=1}^{N} A_{j} \cos \left(\omega_{j} t+c_{j}\right)$,

$\left.\frac{\partial W_{1}}{\partial x}\right|_{x=\infty}=0$

$S \frac{\partial H_{\mathrm{C} 1}}{\partial t}=T \frac{\partial^{2} H_{\mathrm{C} 1}}{\partial x^{2}}+L\left(W_{1}-H_{\mathrm{C} 1}\right)$,

$-\infty<t<\infty, x>0$

$\lim _{x \rightarrow \infty} \frac{\partial H_{\mathrm{C} 1}}{\partial x}=0$,

$\left.H_{\mathrm{C} 1}\right|_{x=0}=\frac{D}{A_{\Sigma}} \sum_{j=1}^{N} A_{j} \cos \left(\omega_{j} t+c_{j}\right) ;$

Order $\delta^{2}$ :

$S_{\mathrm{y}} \frac{\partial W_{2}}{\partial t}=K_{\mathrm{U}} D \frac{\partial^{2} W_{2}}{\partial x^{2}}+K_{\mathrm{U}}\left(W_{1} \frac{\partial^{2} W_{1}}{\partial x^{2}}+\left(\frac{\partial W_{1}}{\partial x}\right)^{2}\right)$

$-L\left(W_{2}-H_{\mathrm{C} 2}\right), \quad-\infty<t<\infty, x>0$,

$\left.W_{2}\right|_{x=0}=0$,

$\left.H_{\mathrm{C} 2}\right|_{x=0}=0$.

The other three equations satisfied by $W_{2}$ and $H_{\mathrm{C} 2}$ are not written out here because they can be obtained 
directly by substituting $W_{1}$ and $H_{\mathrm{C} 1}$ in Eqs. (A8.3)(A8.5) with $W_{2}$ and $H_{\mathrm{C} 2}$, respectively.

Although the exact solution $W_{1}$ to Eqs. (A8.1)(A8.6) has been found ( $\mathrm{Li}$ and Jiao, 2002), here it will be simplified for the sake of succinctness. Using the condition $\varepsilon_{j}=L /\left(\omega_{j} S_{\mathrm{y}}\right) \ll 1$, the exact solution $W_{1}$ of Eqs. (A8.1)-(A8.6) can be simplified into

$W_{1}(x, t)=\frac{D}{A_{\Sigma}} \sum_{j=1}^{N} A_{j} \mathrm{e}^{-a_{j} x}\left(1+\mathrm{O}\left(\varepsilon_{j}\right)\right) \cos \left(\omega_{j} t-a_{j} x+c_{j}\right)$.

(A10.1)

Using Eq. (A8.1) and the periodicity of $W_{1}$, one has

$$
\begin{aligned}
\frac{1}{P} \int_{t}^{t+P} K_{\mathrm{U}} W_{1} \frac{\partial^{2} W_{1}}{\partial x^{2}} \mathrm{~d} t= & \frac{S_{\mathrm{y}}}{2 P D} \int_{t}^{t+P} \frac{\partial W_{1}^{2}}{\partial t} \mathrm{~d} t \\
& +\frac{L}{P D} \int_{t}^{t+P} W_{1}\left(W_{1}-H_{\mathrm{C} 1}\right) \mathrm{d} t \\
= & \frac{L}{P D} \int_{t}^{t+P} W_{1}\left(W_{1}-H_{\mathrm{C} 1}\right) \mathrm{d} t
\end{aligned}
$$

substituting Eq. (A10.1) into the above equation, using $W_{1}-H_{\mathrm{C} 1}=A_{\Sigma} \mathrm{O}(1)$, yield

$$
\frac{1}{P} \int_{t}^{t+P} K_{\mathrm{U}} W_{1} \frac{\partial^{2} W_{1}}{\partial x^{2}} \mathrm{~d} t=\sum_{j=1}^{N} A_{j} \omega_{j} S_{\mathrm{y}} \mathrm{O}\left(\varepsilon_{j}\right) \mathrm{e}^{-a_{j} x} .
$$

(A10.3)

Using Eq. (A10.1) and the trigonometric identities

$2 \sin \phi \cos \psi=\sin (\phi+\psi)-\sin (\phi-\psi)$,

$2 \cos \phi \cos \psi=\cos (\phi+\psi)+\cos (\phi-\psi)$,

one obtains

$$
\begin{aligned}
& \frac{1}{P} \int_{t}^{t+P} K_{\mathrm{U}}\left(\frac{\partial W_{1}}{\partial x}\right)^{2} \mathrm{~d} t \\
& =\frac{D}{2 A_{\Sigma}^{2}} \sum_{j=1}^{N} A_{j}^{2} \omega_{j} S_{\mathrm{y}}\left(1+\mathrm{O}\left(\varepsilon_{j}\right)\right) \exp \left(-2 a_{j} x\right) .
\end{aligned}
$$

Substituting Eq. (A10.1) into Eq. (A9.1), then integrating Eqs. (A9.1)-(A9.3) and other three equations satisfied by $W_{2}$ and $H_{\mathrm{C} 2}$ with respect to $t$ from $t$ to $t+P$, one obtains the time-averaged linear system with respect to $\bar{W}_{2}$ and $\bar{H}_{\mathrm{C} 2}$. Based on Eqs. (A10.2)-(A10.4), the source term of the time-averaged system is

$$
\begin{aligned}
& \frac{1}{P} \int_{t}^{t+P} K_{\mathrm{U}}\left(W_{1} \frac{\partial^{2} W_{1}}{\partial x^{2}}+\left(\frac{\partial W_{1}}{\partial x}\right)^{2}\right) \mathrm{d} t \\
& =\frac{D}{2 A_{\Sigma}^{2}} \sum_{j=1}^{N} A_{j}^{2} \omega_{j} S_{\mathrm{y}}\left(1+\mathrm{O}\left(\varepsilon_{j}\right)\right) \exp \left(-2 a_{j} x\right) .
\end{aligned}
$$

Neglecting terms of $\mathrm{O}\left(\varepsilon_{j}\right)$, the time-averaged system is eventually simplified into

$$
\begin{aligned}
& \bar{W}_{2}^{\prime \prime}-\frac{L}{T_{\mathrm{U}}}\left(\bar{W}_{2}-\bar{H}_{\mathrm{C} 2}\right) \\
& =-\frac{D}{A_{\Sigma}^{2}} \sum_{j=1}^{N} A_{j}^{2} a_{j}^{2} \exp \left(-2 a_{j} x\right), \quad x>0, \\
& \bar{H}_{\mathrm{C} 2}^{\prime \prime}+\frac{L}{T}\left(\bar{W}_{2}-\bar{H}_{\mathrm{C} 2}\right)=0, \quad x>0, \\
& \left.\bar{W}_{2}\right|_{x=0}=0,\left.\quad \bar{W}_{2}^{\prime}\right|_{x=\infty}=0, \\
& \left.\bar{H}_{\mathrm{C} 2}\right|_{x=0}=0,\left.\quad \bar{H}_{\mathrm{C} 2}^{\prime}\right|_{x=\infty}=0,
\end{aligned}
$$

where $T_{\mathrm{U}}=K_{\mathrm{U}} D$. For the $j$ th single source term $-\left(D / A_{\Sigma}^{2}\right) A_{j}^{2} a_{j}^{2} \exp \left(-2 a_{j} x\right)$, the solutions $\bar{W}_{2 j}$ and $\bar{H}_{2 j}$ to the system (A12) are

$$
\begin{aligned}
\bar{W}_{2 j}= & \frac{D A_{j}^{2} a_{j}^{2}}{A_{\Sigma}^{2}}\left[\frac{p_{j} L_{\mathrm{T}}-q_{j} L_{\mathrm{U}}}{L_{\mathrm{T}}+L_{\mathrm{U}}}\right. \\
& +\frac{L_{\mathrm{U}}\left(p_{j}+q_{j}\right) \exp \left(-x \sqrt{L_{\mathrm{T}}+L_{\mathrm{U}}}\right)}{L_{\mathrm{T}}+L_{\mathrm{U}}} \\
& \left.-p_{j} \exp \left(-2 a_{j} x\right)\right], \\
\bar{H}_{2 j}= & \frac{D A_{j}^{2} a_{j}^{2}}{A_{\Sigma}^{2}}\left[\frac{p_{j} L_{\mathrm{T}}-q_{j} L_{\mathrm{U}}}{L_{\mathrm{T}}+L_{\mathrm{U}}}\right. \\
& -\frac{L_{\mathrm{T}}\left(p_{j}+q_{j}\right) \exp \left(-x \sqrt{L_{\mathrm{T}}+L_{\mathrm{U}}}\right)}{L_{\mathrm{T}}+L_{\mathrm{U}}} \\
& \left.+q_{j} \exp \left(-2 a_{j} x\right)\right],
\end{aligned}
$$

where

$L_{\mathrm{T}}=L / T, \quad L_{\mathrm{U}}=L / T_{\mathrm{U}}$ 
$p_{j}=\frac{4 a_{j}^{2}-L_{\mathrm{T}}}{4 a_{j}^{2}\left(4 a_{j}^{2}-L_{\mathrm{U}}-L_{\mathrm{T}}\right)}$,

$q_{j}=\frac{L_{\mathrm{T}}}{4 a_{j}^{2}\left(4 a_{j}^{2}-L_{\mathrm{U}}-L_{\mathrm{T}}\right)}$.

Using Eqs. (A8.1)-(A8.6), it follows that

$\bar{W}_{1}(x)=\bar{H}_{\mathrm{S} 1}(x)=\bar{H}_{\mathrm{C} 1}(x) \equiv 0$.

Implementing the time-averaged transform to both sides of Eqs. (A6) and (A7), then substituting Eqs. (A13.1), (A13.2) and (A14) back into the transform results, one finally obtains the time-averaged solutions $\bar{W}, \bar{H}_{\mathrm{C}}$ and $\bar{H}_{\mathrm{S}}$ given by Eqs. (20), (21) and (10a), respectively.

\section{References}

Bear, J., 1979. Hydraulics of Groundwater, McGraw-Hill, New York, pp. 74-78, 121,93.

Chen, C.X., Jiao, J., 1999. Numerical simulation of pumping tests in multilayer wells with non-darcian flow in the wellbore. Ground Water 37 (3), 465-474.

Church, T.M., 1996. A groundwater route for the water cycle. Nature 380 (18), 579-580.

Hantush, M.S., 1960. Modification of the theory of leaky aquifers. Journal of Geophysical Research 65 (11), 3713-3716.

Jiao, J., Tang, Z., 1999. An analytical solution of groundwater response to tidal fluctuation in a leaky confined aquifer. Water Resources Research 35 (3), 747-751.

Knight, J.H., 1981. Steady period flow through a rectangular dam. Water Resources Research 17 (4), 1222-1224.

Li, H., Jiao, J., 2001. Analytical studies of groundwater-head fluctuation in a coastal confined aquifer overlain by a semi-permeable layer with storage. Advances in Water Resources 24 (5), 565-573.

Li, H., Jiao, J., 2002. Analytical solutions of tidal groundwater flow in coastal two-aquifer system. Advances in Water Resources 25 (4), 417-426

Li, L., Barry, D.A., Stagnitti, F., Parlange, J.-Y., 1999. Submarine groundwater discharge and associated chemical input to a coastal sea. Water Resources Research 35 (11), 3253-3259.

Li, L., Barry, D.A., Stagnitti, F., Parlange, J.-Y., Jeng, D.-S., 2000. Beach water table fluctuations due to spring-neap tides: moving boundary effects. Advances in Water Resources 23, $817-824$

Melchior, P., 1978. The Tides of the Planet Earth, Pergamon Press, London.

Moore, W.S., 1996. Large groundwater inputs to coastal waters revealed by ${ }^{226} \mathrm{Ra}$ enrichment. Nature 380 (18), 612-614.

Nielsen, P., 1990. Tidal dynamics of the water table in beaches. Water Resources Research 26 (9), 2127-2134.

Parlange, J.-Y., Stagnitti, F., Starr, J.L., Braddock, R.D., 1984. Freesurface flow in porous media and periodic solution of the shallow-flow approximation. Journal of Hydrology 70, 251-263.

Philip, J.R., 1973. Periodic nonlinear diffusion: an integral relation and its physical consequences. Australian Journal of Physics 26, 513-519.

Pugh, D.T., 1987. Tides, Surges and Mean Sea-level, Wiley, New York.

Serfes, M.E., 1991. Determining the mean hydraulic gradient of ground water affected by tidal fluctuations. Ground Water 29 (4), 549-555

Sheahan, N.T., 1977. Injection/extraction well system-a unique seawater intrusion barrier. Ground Water 15 (1), 32-49.

Smiles, D.E., Stokes, A.N., 1976. Periodic solutions of a nonlinear diffusion equation used in groundwater flow theory: examination using a Hele-Shaw model,. Journal of Hydrology 31, $27-35$.

Todd, D.K., 1980. Groundwater Hydrology, Wiley, New York, pp. 45. 